\title{
Quantitative Reevaluation of the Effects of Short- and Long-Term Removal of Descending Modulatory Inputs on the Pyloric Rhythm of the Crab, Cancer borealis ${ }^{1,2,3}$
}

\author{
Albert W. Hamood, Sara A. Haddad, Adriane G. Otopalik, Philipp Rosenbaum, and ${ }^{-}$Eve Marder
}

DOI:http://dx.doi.org/10.1523/ENEURO.0058-14.2015

Volen Center and Biology Department, Brandeis University, Waltham, Massachusetts 02545

\begin{abstract}
The crustacean stomatogastric ganglion (STG) receives descending neuromodulatory inputs from three anterior ganglia: the paired commissural ganglia (CoGs), and the single esophageal ganglion (OG). In this paper, we provide the first detailed and quantitative analyses of the short- and long-term effects of removal of these descending inputs (decentralization) on the pyloric rhythm of the STG. Thirty minutes after decentralization, the mean frequency of the pyloric rhythm dropped from $1.20 \mathrm{~Hz}$ in control to $0.52 \mathrm{~Hz}$. Whereas the relative phase of pyloric neuron activity was approximately constant across frequency in the controls, after decentralization this changed markedly. Nine control preparations kept for 5-6 d in vitro maintained pyloric rhythm frequencies close to their initial values. Nineteen decentralized preparations kept for 5-6 d dropped slightly in frequency from those seen at 30 min following decentralization, but then displayed stable activity over $6 \mathrm{~d}$. Bouts of higher frequency activity were intermittently seen in both control and decentralized preparations, but the bouts began earlier and were more frequent in the decentralized preparations. Although the bouts may indicate that the removal of the modulatory inputs triggered changes in neuronal excitability, these changes did not produce obvious long-lasting changes in the frequency of the decentralized preparations.
\end{abstract}

Key words: central pattern generator; homeostatic regulation of excitability; stomatogastric nervous system

\section{Significance Statement}

Neuromodulatory inputs are known to strongly influence the intrinsic excitability of individual neurons and the networks in which the targets of modulation are found. It is therefore important to understand how nervous systems respond to altered neuromodulatory environments. We find that removal of neuromodulatory inputs from the stomatogastric ganglion of wild-caught Cancer borealis decreases frequency and alters phase relationships of the pyloric rhythm within $30 \mathrm{~min}$, and that these changes persist across time. Previous reports from several species suggested that the pyloric rhythm of crustaceans compensates for this loss and recovers intact activity patterns; our dataset suggests that this perturbation is not compensated. Caution is necessary when interpreting results from wild-caught populations, which may be unstable over time. 


\section{Introduction}

A fundamental but unresolved issue in neuroscience is how neurons and networks respond to the reduction or total loss of neuromodulatory inputs. The crustacean stomatogastric nervous system has been an extraordinarily useful preparation for the study of the fundamental mechanisms of central pattern generation, neuromodulation, and response to the removal of neuromodulatory inputs (Selverston et al., 1976; Selverston and Moulins, 1985, 1987; Harris-Warrick et al., 1992; Marder and Bucher, 2007). In the lobster, Panulirus interruptus, the importance of descending inputs from the paired commissural ganglia (CoGs) to the single stomatogastric ganglion (STG) for the generation of robust gastric mill and pyloric rhythms was first highlighted by reversible block of the stomatogastric nerve (stn) (Russell, 1976, 1979). This resulted in loss of gastric mill activity and decreases in the cycle frequency (subsequently referred to simply as frequency) of the pyloric rhythm, within minutes. Similar results have been subsequently obtained in a variety of crab and lobster species, although in some species, after removal of the descending inputs (decentralization), there may be a stronger tendency for the pyloric rhythm to fall silent (Moulins and Cournil, 1982; Bal et al., 1994).

The crab, Cancer borealis, has been used for a large number of studies of the effects of neuromodulators and neuromodulatory neurons (Nusbaum et al., 2001; Nusbaum and Beenhakker, 2002; Marder and Bucher, 2007; Blitz and Nusbaum, 2011, 2012). In C. borealis, there have been anecdotal reports that decentralization can result either in a decrease in the frequency of the pyloric rhythm, or its complete cessation. Because the effects of excitatory neuromodulators are more easily seen when the pyloric rhythm is either very slow or stopped, the specific examples used as figures demonstrating the effects of neuromodulators in the literature have been inadvertently biased towards preparations with less robust pyloric rhythms after decentralization. Consequently, this has fostered the perception that decentralization in C. borealis routinely results in the loss of all pyloric rhythm activity, although there have been no large data sets that address this issue. This has prompted us, in the first section of this paper, to provide data from more than a hundred preparations showing, for the first time, a quantitative analysis of the effects of short-term removal of the descending

Received November 20, 2014; accepted January 9, 2015; First published January 14, 2015

${ }^{1}$ Author contributions: A.W.H. and E.M. designed research; A.W.H., S.A.H., A.G.O., and P.R. performed research; A.W.H. analyzed data; A.W.H. and E.M. wrote the paper.

${ }^{2}$ This work was supported by grants from NINDS (F31 NS 080420, A.W.H.) and NIMH (R01 MH 46742, S.A.H., A.G.O., P.R., E.M.).

${ }^{3}$ The authors report no conflicts of interest.

Correspondence should be addressed to Albert W. Hamood, Volen Center and Biology Department, M.S. 013, Brandeis University, 415 South Street, Waltham, MA 02454. E-mail: alhamood@brandeis.edu.

DOI:http://dx.doi.org/10.1523/ENEURO.0058-14.2015

Copyright @ 2015 Hamood et al.

This is an open-access article distributed under the terms of the Creative Commons Attribution 4.0 International, which permits unrestricted use, distribution and reproduction in any medium provided that the original work is properly attributed. modulatory inputs. Quantitative data reporting the frequency and phase relationships of pyloric rhythms in $C$. borealis in the presence of the descending modulatory inputs were recently reported (Goaillard et al., 2009), and the control data in this study are largely consistent with those data.

Stomatogastric nervous system preparations can survive for many days after removal from the animal (ThobyBrisson and Simmers, 1998, 2000, 2002; Golowasch et al., 1999b; Mizrahi et al., 2001; Luther et al., 2003; MacLean et al., 2003, 2005; Zhang et al., 2003). This creates the remarkable opportunity to use these preparations to study the effects of long-term removal of neuromodulation and the resultant decrease in activity on the circuits that are the direct targets of that neuromodulation.

It is now clear that extended periods of time deprived of neuromodulatory inputs trigger changes in excitability and gene expression (Mizrahi et al., 2001; Thoby-Brisson and Simmers, 2002; Temporal et al., 2012, 2014) in preparations from several species. There are previous reports that preparations that fall silent after decentralization recover rhythmic activity over several days (Thoby-Brisson and Simmers, 1998, 2000, 2002; Golowasch et al., 1999a; Luther et al., 2003), as would be expected if changes in excitability and gene expression that are triggered by removal of the descending inputs allow the STG to retune, using homeostatic or other rules to resume more normal function (Golowasch et al., 1999a; Luther et al., 2003; Zhang and Golowasch, 2007, 2011; Zhang et al., 2009;).

The increased computer power available today makes it possible to record continuously from preparations for days and weeks. We now report quantitative analyses of data from continuous recordings of STGs from C. borealis that show many features of the data previously reported and interpreted as recovery of normal pyloric activity. Nonetheless, these new data are more consistent with the interpretation that each animal maintains a relatively stable level of activity over several days after decentralization, although it is highly likely that numerous changes in system parameters are occurring during this time frame that, in principle, could support recovery of function in some preparations, had they lost rhythmic activity in a short time after decentralization.

\section{Materials and Methods}

\section{Animals}

Adult male Cancer borealis were purchased from Commercial Lobster and communally housed in artificial seawater at $10-12{ }^{\circ} \mathrm{C}$ until used, generally within 1 week of arrival. On the first day of the experiments, crabs were anesthetized by storing in ice for $30 \mathrm{~min}$ prior to the dissection. Animals used in this study were from May 2011 to November 2014, with most from 2013 and 2014.

\section{Saline composition}

C. borealis physiological saline included $440 \mathrm{mM} \mathrm{NaCl}$, $11 \mathrm{mM} \mathrm{KCl}, 13 \mathrm{mM} \mathrm{CaCl}_{2}, 26 \mathrm{mM} \mathrm{MgCl}, 11 \mathrm{mM}$ Trizma base, and $5 \mathrm{mM}$ Maleic acid. For long-term experiments, this saline was supplemented with $5.5 \mathrm{mM}$ dextrose, 50 
Table 1 Pearson correlations

\begin{tabular}{|c|c|c|c|}
\hline Data & $n$ & $R$ & $p$ value \\
\hline Intact, Hz vs PD off & 123 & 0.4113 & 1.19E-05 \\
\hline Intact, Hz vs LP on & 123 & 0.0555 & 0.5759 \\
\hline Intact, Hz vs LP off & 123 & 0.3422 & 3.77E-04 \\
\hline Decentralized, Hz vs PD off & 115 & 0.8229 & $<1 \mathrm{E}-06$ \\
\hline Decentralized, Hz vs LP on & 115 & 0.8298 & $<1 \mathrm{E}-06$ \\
\hline Decentralized, Hz vs LP off & 115 & 0.8295 & $<1 \mathrm{E}-06$ \\
\hline Intact, $\mathrm{Hz}$ vs 30 min decentralized $\mathrm{Hz}$ & 115 & 0.4077 & $6.1049 \mathrm{E}-06$ \\
\hline 30 min decentralized $\mathrm{Hz}$ vs $2 \mathrm{~d}$ decentralized $\mathrm{Hz}$ & 19 & 0.5234 & 0.0258 \\
\hline 2 d decentralized $\mathrm{Hz}$ vs $3 \mathrm{~d}$ decentralized $\mathrm{Hz}$ & 19 & 0.6046 & 7.90E-03 \\
\hline $3 \mathrm{~d}$ decentralized $\mathrm{Hz}$ vs $4 \mathrm{~d}$ decentralized $\mathrm{Hz}$ & 19 & 0.4249 & 0.0788 \\
\hline $5 \mathrm{~h}$ recovery time vs time to first bout & 19 & 0.151 & 0.537 \\
\hline
\end{tabular}

$\mu \mathrm{g} / \mathrm{ml}$ penicillin/streptomycin (Gibco, Reference 15140148), and $500 \mathrm{ng} / \mathrm{ml}$ fungizone (Amphotericin B, Omega Scientific, Catalog No. FG-70).

\section{In vitro long-term recordings}

Petri dishes were disinfected by UV light for at least 30 min prior to use, and dissection tools were soaked in $70 \%$ ethanol. Intact stomatogastric nervous systems (STNS), including the STG, the bilateral commissural ganglia (CoGs), and the esophageal ganglion (OG) were dissected and pinned out on a Sylgard-coated Petri dish, and maintained in continuously superfused physiological saline containing antibiotics. Vaseline wells were built around the motor nerves containing the axons for the motor neurons of the pyloric rhythm, including the lateral ventricular nerve (Ivn) and the pyloric dilator nerve (pdn). Preparations were then placed in a humidity-controlled environmental chamber and held at $12{ }^{\circ} \mathrm{C}$, while fresh saline was continuously superfused at a rate of 300-500 $\mathrm{ml}$ per day. After recording $1 \mathrm{~h}$ of baseline data, decentralization was accomplished by transection of the stn approximately midway between the STG and the OG. In some cases (6/19), the severed anterior ganglia were removed from the dish following decentralization; this procedure did not qualitatively change any result. Dishes were then covered with parafilm and left otherwise undisturbed for the duration of the experiments while recordings continued. Fresh saline was pipetted into the Vaseline wells each day. This protocol reliably maintained a healthy STNS for long periods of time, lasting up to several weeks.

\section{Acute decentralization}

After dissecting the STNS as described above, preparations were pinned out onto Sylgard-coated Petri dishes with Vaseline wells built around at least the Ivn, and recordings were made during continuous superfusion of physiological saline at $10-12{ }^{\circ} \mathrm{C}$. The superfusion rates often used in the acute experiments $(1-10 \mathrm{ml} / \mathrm{min})$ were considerably greater than those used in long-term experiments. Decentralization was accomplished by either transection of the stn, blockade of the stn with TTX $\left(10^{-7} \mathrm{M}\right)$, or both. No qualitative differences were observed as a result of the method of decentralization, nor the experimenter.

\section{Electrophysiological recordings}

Data were acquired using a Digidata 1440 digitizer (Axon Instruments), a model 3500 extracellular amplifier (A-M Systems), and pClamp data acquisition software (Axon Instruments, version 10). Recordings always contained at least the pdn and Ivn nerves, or a sufficiently clean recording of the Ivn nerve alone that allowed for unambiguous detection of burst properties for the pyloric dilator (PD) and lateral pyloric (LP) units of the pyloric rhythm.

\section{Data analysis}

Data were analyzed offline using custom scripts written in Spike2 (Cambridge Electronic Design, version 7) and Matlab (Mathworks, version 2013b). These scripts allowed for semi-automated detection of burst timing in PD and LP neurons. Phase relationships were quantified relative to PD start. For individual long-term plots of frequency against time, the median frequencies of $6 \mathrm{~min}(0.1$ h) bins of pyloric data are plotted. For ANOVAs involving LP neurons, preparations in which LP was silent were not plotted as points in figures showing LP phase; pyloric rhythms lacking LP neuron activity were rare. Box plots show the median and first and third quartile of the given data, while whiskers extend to the most extreme datum within 1.5 times the interquartile range from the nearest quartile. Outliers are shown with an X.

\section{Statistics}

Assessment of changes caused by decentralization was done by two-way, mixed-model ANOVA on averaged data binned across the first $6 \mathrm{~d}$ of recordings. Decentralization state was treated as a between-subjects factor, and time was treated as a within-subjects factor. Pairwise comparisons of groups were done by paired $t$ tests when possible; unpaired, independent samples $t$ tests were used when groups were not matched but had similar n's and variances. Mood's median test was used for comparing groups of much different sizes and variances. Correlation $R$ and $p$ values are reported from linear Pearson correlations. All tests were computed in Matlab (Mathworks, version 2013b), and significance was assessed at the $p<0.05$ level (Tables 1, 2, 3, 4). 
Table $2 t$ tests

\begin{tabular}{|c|c|c|c|}
\hline Data & $n$ & $t$ & $p$ value \\
\hline \multicolumn{4}{|l|}{ Paired $t$ tests } \\
\hline Intact Pyloric $\mathrm{Hz}$ vs 30 min decentralized $\mathrm{Hz}$ & 115 & 40.768 & $<1 \mathrm{E}-06$ \\
\hline $\begin{array}{l}\mathrm{Hz} \text {, pre- vs post-saline exchanges (avg) } \\
\text { Unpaired } t \text { tests }\end{array}$ & 10 & -5.2897 & $5.01 \mathrm{E}-04$ \\
\hline Time-matched vs saline-exchange pre & 13 matched; 10 exchanged & -2.4662 & 0.028 \\
\hline Time-matched vs saline-exchange post & 13 matched; 10 exchanged & -5.2897 & 5.01E-04 \\
\hline
\end{tabular}

Table 3 Mixed-model ANOVAs

\begin{tabular}{|c|c|c|c|c|c|c|c|}
\hline Data & $n$ & $\begin{array}{l}\text { Between- } \\
\text { subjects } F\end{array}$ & $\begin{array}{l}\text { Between- } \\
\text { subjects } p\end{array}$ & $\begin{array}{c}\text { Within- } \\
\text { subjects } F\end{array}$ & $\begin{array}{c}\text { Within- } \\
\text { subjects } p\end{array}$ & $\begin{array}{c}\text { Interaction } \\
F\end{array}$ & $\begin{array}{c}\text { Interaction } \\
p\end{array}$ \\
\hline$\overline{\text { Pyloric Hz }}$ & $19 ; 9$ & 108.12 & $<1 \mathrm{E}-06$ & 1.632 & 0.1578 & 1.775 & 0.1234 \\
\hline Cycle variation & $19 ; 9$ & 5.134 & 0.0347 & 0.426 & 0.82975 & 0.365 & 0.87119 \\
\hline PD off & $19 ; 9$ & 24.944 & 6.07E-05 & 0.254 & 0.93719 & 0.703 & 0.6226 \\
\hline LP on & $19 ; 9$ & 5.382 & 0.0489 & 0.687 & 0.63616 & 0.702 & 0.625 \\
\hline LP off & $19 ; 9$ & 9.234 & 0.016 & 2.175 & 0.076 & 0.55 & 0.7376 \\
\hline Bouts & $19 ; 9$ & 9.417 & 6.06E-03 & 7.337 & $6.8 \mathrm{E}-06$ & 6.393 & $3.42 \mathrm{E}-06$ \\
\hline
\end{tabular}

Table 4: Mood's median tests

\begin{tabular}{|c|c|c|c|}
\hline Data & $n$ & $\chi^{2}$ & $p$ value \\
\hline $\begin{array}{l}\text { Fastest } 5 \mathrm{~h} \text { decentralized vs } \\
\text { intact Pyloric } \mathrm{Hz}\end{array}$ & $\begin{array}{l}195 \text {-h decentralized stretches; } \\
123 \text { intact }\end{array}$ & 17.56 & $2.78 \mathrm{E}-05$ \\
\hline $\begin{array}{l}\text { Fastest } 5 \mathrm{~h} \text { decentralized vs } \\
\text { intact cycle variation }\end{array}$ & $\begin{array}{l}195 \text {-h decentralized stretches; } \\
123 \text { intact }\end{array}$ & 21.935 & 2.82E-06 \\
\hline $\begin{array}{l}\text { Fastest } 5 \text { h decentralized vs } \\
\text { intact PD off }\end{array}$ & $\begin{array}{l}195-h \text { decentralized stretches; } \\
123 \text { intact }\end{array}$ & 17.6187 & 2.70E-05 \\
\hline $\begin{array}{l}\text { Fastest } 5 \text { h decentralized vs } \\
\text { intact LP on }\end{array}$ & $\begin{array}{l}195 \text {-h decentralized stretches; } \\
123 \text { intact }\end{array}$ & 8.1044 & 4.40E-03 \\
\hline $\begin{array}{l}\text { Fastest } 5 \mathrm{~h} \text { decentralized vs } \\
\text { intact LP off }\end{array}$ & $\begin{array}{l}195 \text {-h decentralized stretches; } \\
123 \text { intact }\end{array}$ & 11.6703 & 6.35E-04 \\
\hline $\begin{array}{l}\text { Fastest } 5 \mathrm{~h} \text { decentralized vs } 30 \\
\text { min decentralized } \mathrm{Hz}\end{array}$ & $\begin{array}{l}19 \text { 5-h decentralized stretches; } \\
115 \text { 30-min decentralized }\end{array}$ & 1.5332 & 0.2156 \\
\hline $\begin{array}{l}\text { Fastest } 5 \text { h decentralized vs } 30 \\
\text { min decentralized cycle } \\
\text { variation }\end{array}$ & $\begin{array}{l}19 \text { 5-h decentralized stretches; } \\
115 \text { 30-min decentralized }\end{array}$ & 5.1989 & 0.0226 \\
\hline $\begin{array}{l}\text { Fastest } 5 \text { h decentralized vs } 30 \\
\text { min decentralized PD off }\end{array}$ & $\begin{array}{l}19 \text { 5-h decentralized stretches; } \\
115 \text { 30-min decentralized }\end{array}$ & 1.5585 & 0.2119 \\
\hline $\begin{array}{l}\text { Fastest } 5 \mathrm{~h} \text { decentralized vs } 30 \\
\text { min decentralized LP on }\end{array}$ & $\begin{array}{l}195 \text {-h decentralized stretches; } \\
115 \text { 30-min decentralized }\end{array}$ & 1.348 & 0.2456 \\
\hline $\begin{array}{l}\text { Fastest } 5 \mathrm{~h} \text { decentralized vs } 30 \\
\text { min decentralized LP off }\end{array}$ & $\begin{array}{l}19 \text { 5-h decentralized stretches; } \\
11530 \text {-min decentralized }\end{array}$ & 1.348 & 0.2456 \\
\hline
\end{tabular}

\section{Results}

\section{Decentralization reduces cycle frequency and alters phase relationships in the pyloric rhythm}

Figure $1 \mathrm{~A}$ shows a schematic diagram of the stomatogastric nervous system including the STG, which contains the circuit that drives the pyloric rhythm of the crab C. borealis. The rhythm consists of triphasic alternation between the bursting outputs of three components. The first component includes two PD neurons and a single anterior burster neuron $(A B)$, which are electrically coupled and fire together, forming the pacemaker kernel of the network. Rhythmic inhibition from these neurons then drives bursting activity in follower neurons: a single LP neuron, which fires a burst of action potentials following the PD/AB burst; and a set of several pyloric constrictor (PY) neurons, which fire as the third component of the rhythm. The PD, LP, and PY neurons are motor neurons whose bursting activity drives rhythmic contractions of musculature in the stomach (Maynard, 1972; Maynard and Dando, 1974), and are also the core of the pattern-generating circuit, with many reciprocal inhibitory connections between them (Eisen and Marder, 1982). The axons of these neurons project through motor nerves that can be identified by their muscular targets, allowing activity in the network to be monitored extracellularly without disturbing somata within the STG.

Neuromodulatory inputs to the STG arrive through a single input nerve, the stn (Fig. 1A). Figure 1B shows a typical example of raw data recorded extracellularly from 
A

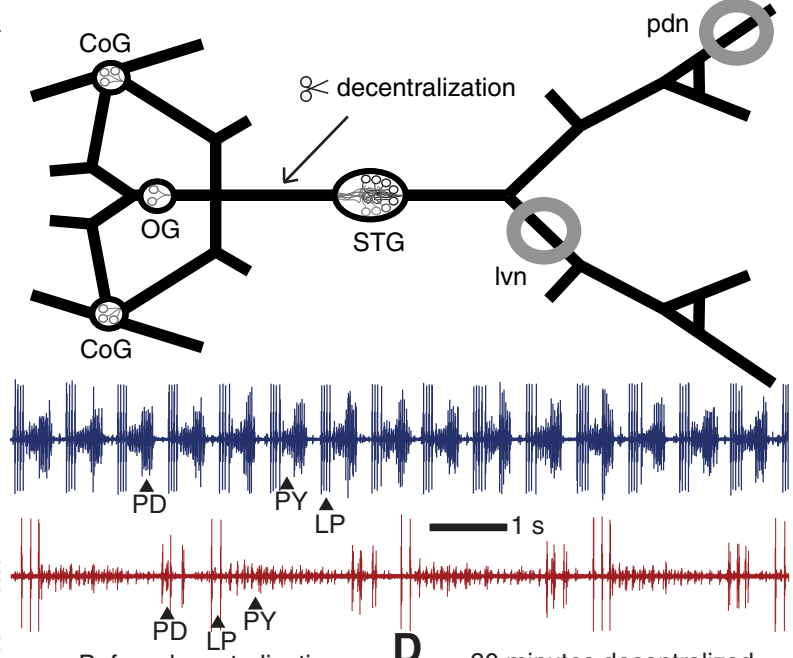

C
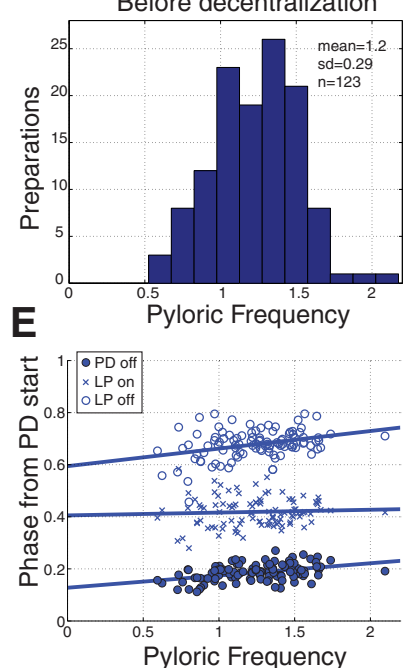

D 30 minutes decentralized
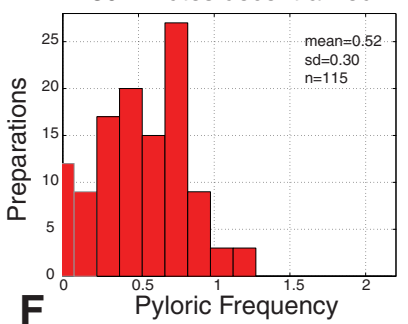

Figure 1 Acute effects of decentralization on the pyloric rhythm. $\boldsymbol{A}$, Schematic diagram of the dissected STNS, as pinned out for recording, showing the location of the STG and its associated anterior modulatory ganglia (CoG, OG). Grey circles identify where Vaseline wells were built for monitoring pyloric activity extracellularly. Decentralization was accomplished by blocking or transecting the stn at the indicated location. $\boldsymbol{B}$, Example Ivn recordings from a preparation before (blue trace) and 30 min following decentralization (red trace). $\boldsymbol{C}, \boldsymbol{D}$, Histograms of pyloric cycle frequencies immediately before decentralization $(\boldsymbol{C}$, blue bars) and $30 \mathrm{~min}$ after ( $\boldsymbol{D}$, red bars). $\boldsymbol{E}, \boldsymbol{F}$, Phase relationships among the PD and LP cells in the pyloric rhythm for intact $(\boldsymbol{E}$, blue) and 30 min decentralized $(\boldsymbol{F}$, red) preparations. Lines represent fits by linear regression.

the Ivn both before (blue trace) and shortly after (red trace) the acute removal of the effects of these modulatory inputs by decentralization. This preparation displayed a greatly reduced pyloric frequency following the perturbation, but maintained its characteristic triphasic rhythm. Consistent with previous reports, all preparations examined exhibited a reduced pyloric frequency following the removal of modulatory inputs.

Population frequency data are summarized in histograms in Figure 1C (intact preparations, blue) and Figure
1D (preparations decentralized for $30 \mathrm{~min}$, red). Mean pyloric cycle frequency was significantly decreased following decentralization $(1.2 \pm 0.29 \mathrm{~Hz}$ before, $0.52 \pm 0.30$ $\mathrm{Hz}$ after, $p<0.001)$. However, a complete cessation of rhythmic activity was rare; less than $10 \%$ of preparations $(9 / 115)$ displayed no rhythmic activity at 30 min postdecentralization. These data were collected by four different experimenters, over 2 years, and with variable protocols for decentralization, which involved either a TTX block of the stn, a complete transection of the input nerve, or both. Qualitatively, no differences in the effect of decentralization were observed as a result of any of these variables.

Phase relationships were also altered 30 min following decentralization (Fig. 1E,F). For intact preparations, pyloric phase was largely conserved across observed frequencies, consistent with previous reports (Bucher et al., 2005; Goaillard et al., 2009). However, this larger dataset did reveal small but statistically significant correlations between pyloric frequency and PD off-phase $(R=0.41, p$ $<0.001)$ and LP off-phase $(R=0.34, p<0.001)$ (Fig. 1E). Interestingly, there was no correlation observed between pyloric frequency and LP on-phase $(R=0.055, p=0.58)$, suggesting that this relationship may be a particularly important target of phase conservation in the pyloric rhythm.

Almost all previous studies that showed that the phase relationships of pyloric neuron activity were relatively independent of frequency across preparations were done on preparations with relatively high frequency rhythms, and with the anterior ganglia attached (Bucher et al., 2005; Goaillard et al., 2009; Tang et al., 2010). Following decentralization, pyloric phase relationships were less conserved, and stronger and steeper correlations were observed between pyloric frequency and PD off-phase $(R$ $=0.82, p<0.001)$ and LP off-phase $(R=0.83, p<$ $0.001)$. A strong correlation with frequency also emerged for LP on-phase $(R=0.83, p<0.001)$ (Fig. 1F).

\section{Long-term recordings reveal varied activity following decentralization}

Previous work on decentralized preparations of the STNS lacked quantitative descriptions, at the population level, of the rhythms generated continuously over many days. We maintained preparations of the STNS and recorded continuously for long durations lasting up to hundreds of hours (4-6 d or longer), superfusing saline throughout. We then compared the behavior of decentralized preparations across these long time-scales to that of intact, control preparations. Figure 2 shows example raw traces from the Ivn of an intact preparation (blue traces, left) and a decentralized preparation (red traces, right) spanning the first $5 \mathrm{~d}$ in culture. This intact preparation maintained its rhythmic character and approximate cycle frequency throughout the experiment. Following decentralization, the preparation on the right displayed a slower frequency at $30 \mathrm{~min}$, which was further reduced at $24 \mathrm{~h}$. Subsequently, this preparation maintained a slower, more variable rhythm for the duration of the experiment. 


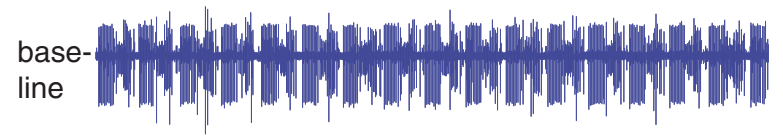

$30 \mathrm{~m}$

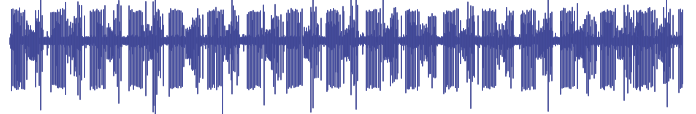

$24 \mathrm{~h}$

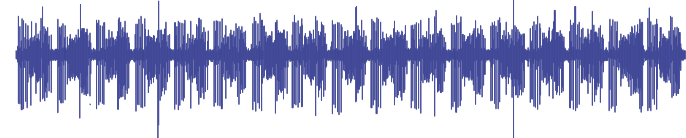

$48 \mathrm{~h}$

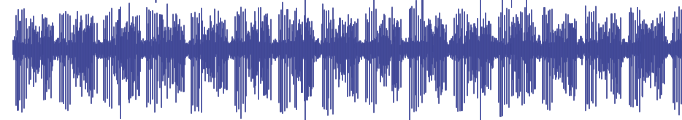

$72 \mathrm{~h}$

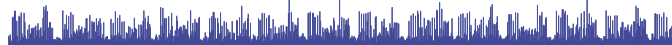

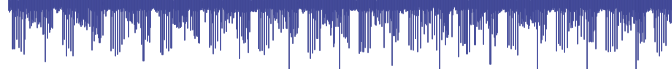

$96 \mathrm{~h}$

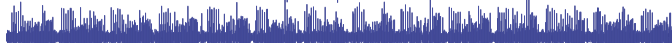

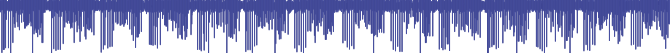

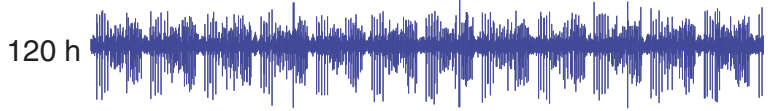

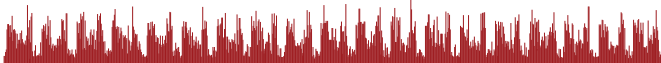

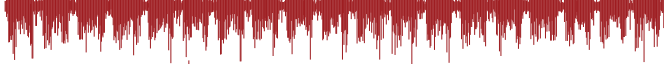
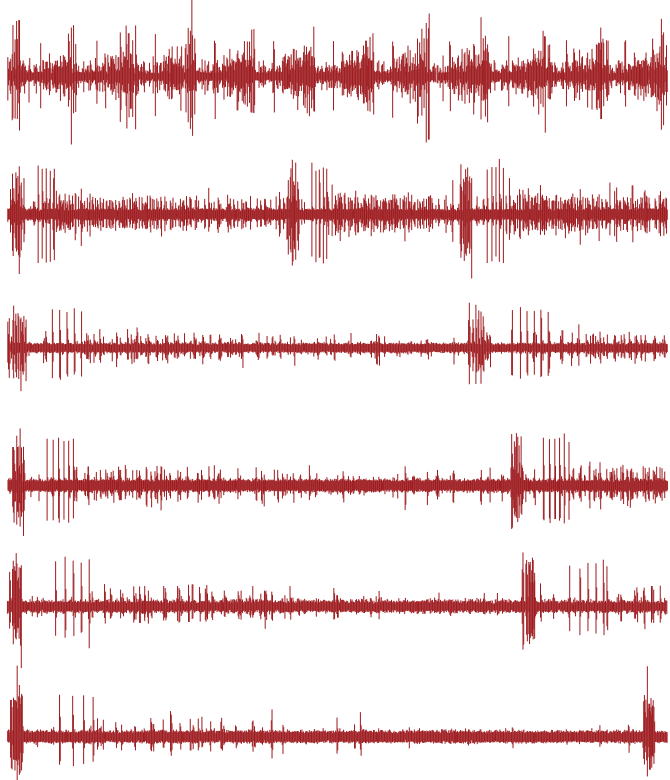

Figure 2 Long-term, continuous extracellular recordings of preparations of the STNS reveal stable behavior. Example $15 \mathrm{~s}$ Ivn traces from two preparations, one in which with the stn left intact throughout the experiment (blue traces, left), and one in which the stn was transected shortly after the baseline recording (red traces, right).

Figure 3 shows frequency against time plots for a number of examples of preparations maintained in this way, including the preparations shown in Figure 2 (intact example, Fig. 3A; decentralized example, Fig. 3E). Pyloric rhythms from intact preparations (blue traces, Fig. 3A-D) tended to maintain a frequency close to their original frequencies. Conversely, decentralized preparations (red traces, Fig. 3E-L) slowed rapidly following the removal of modulatory inputs, and then tended to approximately maintain this lowered frequency for the duration of the experiment. While intact preparations tended to behave similarly across animals and exhibit lower variation in their frequency output across time, decentralized rhythms were considerably more variable. Some preparations maintained a steady, lower-frequency rhythm throughout (Fig. 3G,H), while others exhibited wide variation in their frequency output on long time-scales (Fig. $3 \mathrm{~J}-\mathrm{L}$ ) or short time-scales (Fig. 3E,I). While some preparations exhibited periods of complete silence (Fig. 3F, 3J), most had observable, slow pyloric rhythms at all times during these experiments. Excursions into the frequency range exhibited by intact preparations were rare (Fig. 3L, hours 75115) and transient.

\section{Decentralized preparations do not recover intact-like pyloric rhythms}

Figure 4 summarizes population data for the pyloric rhythm in long-term intact (blue data) and decentralized (red data) preparations of the STNS. Figure 4A shows hourly box plots of pyloric cycle frequency for intact preparations (blue, $n=9$ ) and decentralized preparations (red, $n=19$ ) extending through the first $6 \mathrm{~d}$. These groups rapidly diverged following decentralization, and remained so throughout, with little change through time in the frequency distributions for either group. Little overlap between the frequency ranges was observed, although one decentralized outlier produced a fast rhythm for many hours (see also Fig. 3L).

To assess the degree to which individual preparations varied in their frequency across time, we plotted correlations in pyloric frequencies across time (Fig. 4B-E). This also allowed us to address the hypothesis that slower preparations, which fall silent or near-silent, will better engage compensatory mechanisms and recover faster rhythms than those that do not lose their rhythmic character following decentralization. From immediately before decentralization to $30 \mathrm{~min}$ following decentralization, a significant positive correlation was observed (Fig. 4B, $p<$ 0.001 ), indicating that faster intact rhythms tended to also be among the faster decentralized rhythms. All preparations were markedly slower, as can be observed by comparison to the unity line. However, as measured by the correlation $R$ value, these correlations were stronger at later time-points following decentralization. When comparing frequencies at $30 \mathrm{~min}$ following decentralization to the average frequency observed during the second day (hours 24-48, Fig. 4C), a significant correlation was observed $(p<0.0258)$ and all preparations again exhibited slower rhythms. Thus, the slow-down process is not yet complete at 30 min following decentralization. Nonethe- 

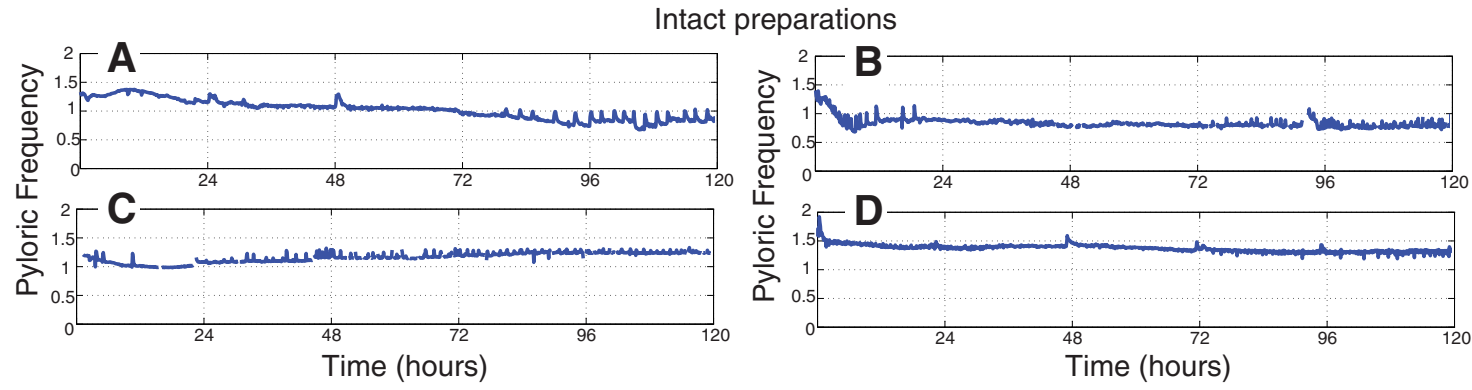

Decentralized preparations
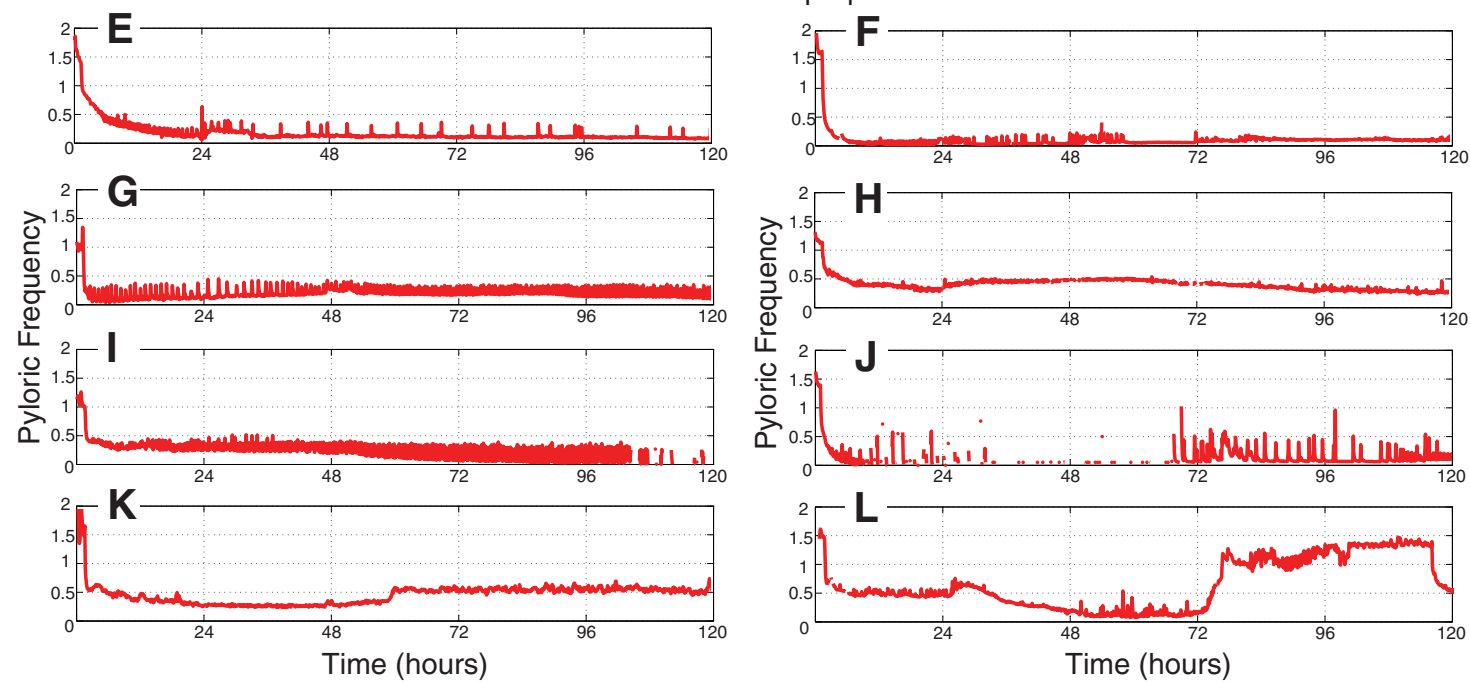

Figure 3 Example long-term pyloric cycle frequency plots of intact $(\boldsymbol{A}-\boldsymbol{D})$ and decentralized $(\boldsymbol{E}-\boldsymbol{L})$ preparations of the STNS. Data are plotted after binning frequencies into $0.1 \mathrm{~h}$ bins. Intact preparations (blue) tend to maintain stable pyloric rhythms with frequencies in the normal range of controls. Decentralized preparations (red) display more varied and variable behavior. Decentralization was accomplished approximately $1 \mathrm{~h}$ following the beginning of these recordings.

less, relatively few of these preparations exhibited a complete loss of pyloric rhythmicity. On subsequent days, pyloric frequency was highly correlated within preparations, and preparations were equally likely to increase or decrease frequency from one day to the next (Fig. 4D,E). Thus, we found no evidence that preparations that become slower recover more effectively to faster frequencies; preparations that became very slow following decentralization tended to remain so on subsequent days.

We next quantified the degree to which features of the pyloric rhythm changed over time and as a result of decentralization to look for quantitative evidence of recovery at the population level. We binned pyloric data within preparations by day and assessed the observed changes by a two-way, mixed-model ANOVA (see Materials and Methods, above). Decentralization significantly decreased pyloric cycle frequency (Fig. 4F, $p<$ 0.001 ), PD off-phase (Fig 4I, $p<0.001$ ), LP on-phase (Fig. $4 \mathrm{~J}, p=0.048$ ), and LP off-phase (Fig. 4K, $p=$ 0.016 ), and significantly increased variability both within preparations (Fig. $4 \mathrm{H}, p=0.035$ ) and across preparations, as measured by the coefficient of variation (Fig. 4G). However, there was no significant effect of time on any of these features, nor was there any significant interaction between time and modulatory condition. Decentralization produced quantitative changes in the pyloric rhythm that did not decrease for as long as these experiments were run, suggesting that the rapid changes induced by decentralization were not compensated for within the conditions of the experiment.

\section{Bouting is increased following decentralization, and increases over time}

Previous work on decentralization in the STG has described bouting, a phenomenon in which decentralized preparations experience transient increases in pyloric frequency (Golowasch et al., 1999b; Luther et al., 2003; Zhang et al., 2009), which were thought to precede a stable recovery. Indeed, the time to first observed bout has been used as a proxy for recovery (Zhang et al., 2009).

To quantify the bouts seen in our long-term recordings, we applied the previously used definition for bouts (Luther et al., 2003), in which a bout was defined as three or more pyloric cycles with a $>40 \%$ increase relative to the background frequency. We computed background frequency as a trailing average of 10 pyloric cycles, and compared it to the following three pyloric cycles. A bout was recorded if all three of the following cycles exhibited at least a $40 \%$ increase from the mean of the previous ten. 
A
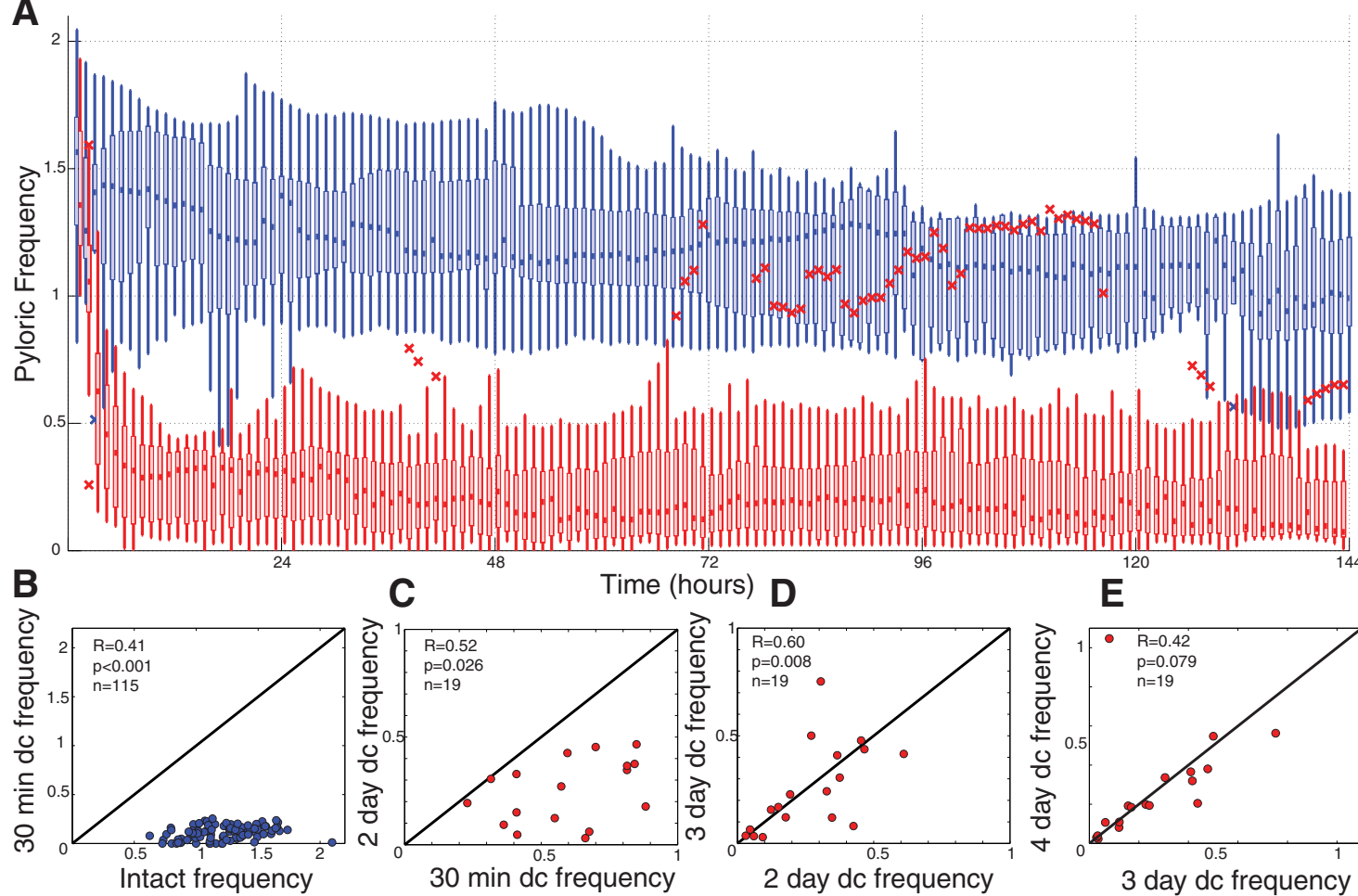

C

Time (hours) D

E
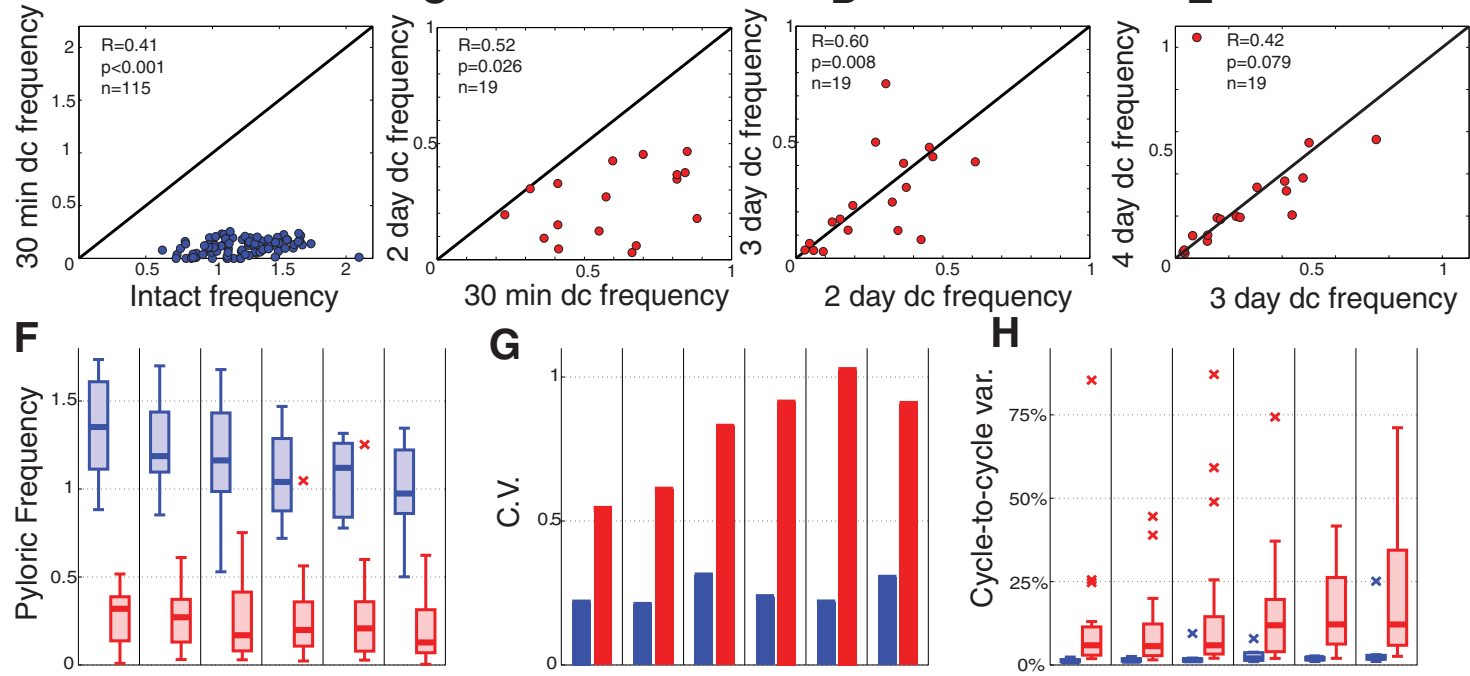

G
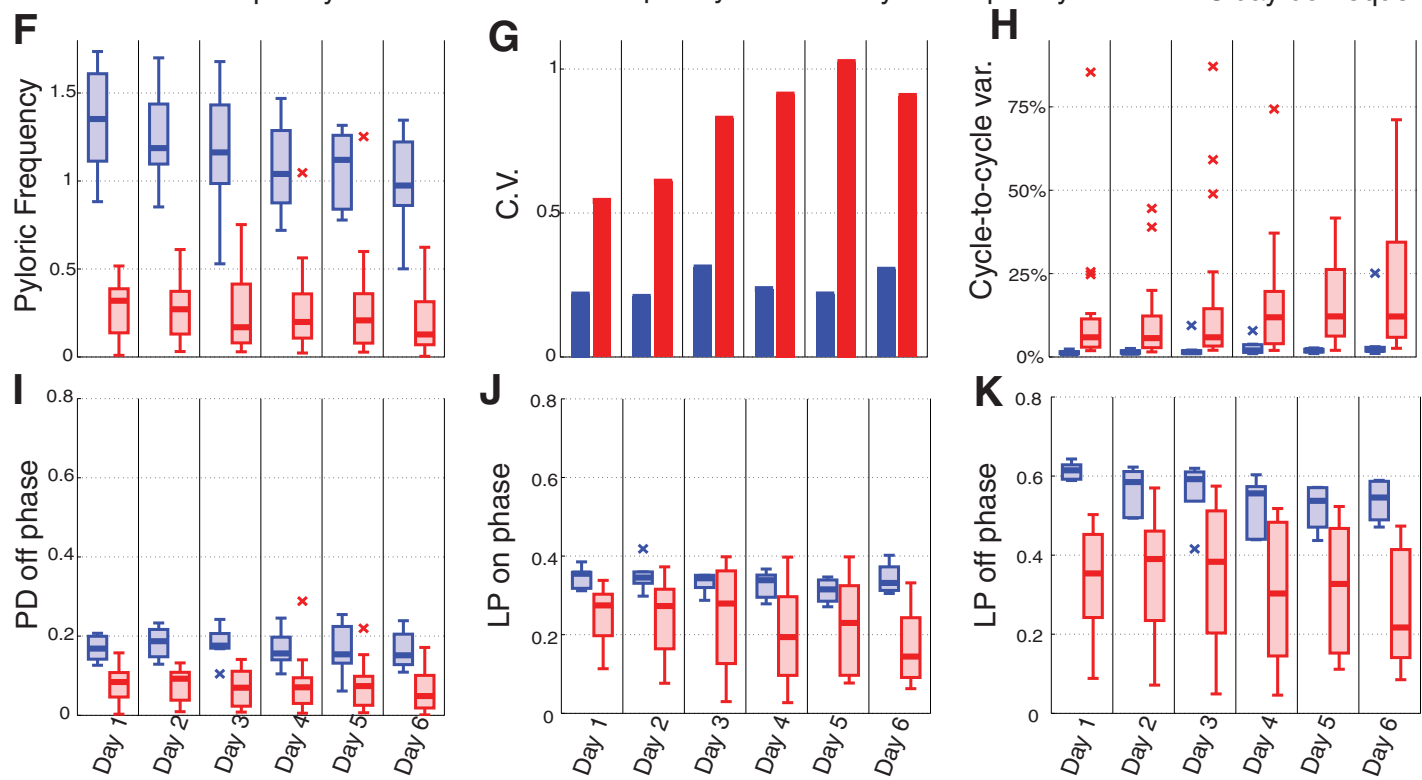

Figure 4 Long-term population effects of decentralization on the pyloric rhythm. $\boldsymbol{A}$, Population data for intact $(n=9)$ and decentralized $(n=19)$ preparations is shown for the first $6 \mathrm{~d}$ in culture. Data are plotted as box plots (see Materials and Methods) for each hour; data from intact preparations are shown in blue while decentralized preparations are shown in red. $\boldsymbol{B}-\boldsymbol{E}$, Cycle frequency correlations within preparations across time (dc, decentralized). Black diagonal line represents unity. Insets report $R$ and $p$ values of Pearson correlations. $\boldsymbol{B}$, Following decentralization, all preparations exhibit a lower pyloric cycle frequency. $\boldsymbol{C}$, All examined preparations also exhibit a lower frequency on the second day following decentralization (average frequency, 24-48 h). $\boldsymbol{D}, \boldsymbol{E}$, On subsequent days, preparations are more correlated, and show an equal tendency to increase or decrease frequency. $\boldsymbol{F}-\boldsymbol{K}$, Measures of frequency $(\boldsymbol{F})$, across-preparation variability (coefficient of variation (C.V.), G), within-preparation variability $(\boldsymbol{H})$, and pyloric phase relationships $(\boldsymbol{I}-\boldsymbol{K})$ are plotted for intact (blue) and decentralized (red) preparations. Box plots are created from population data consisting of the average value for each preparation in $24 \mathrm{~h}$ bins following decentralization.

Figure $5 \mathrm{~A}$ shows a 5 min stretch of raw data from the lvn of a decentralized preparation containing a frequency bout. The corresponding frequency versus time plot is shown below (Fig. 5B) and the arrow represents the point at which this bout was detected. Summary population data for bouting are shown in Figure 5C. As 


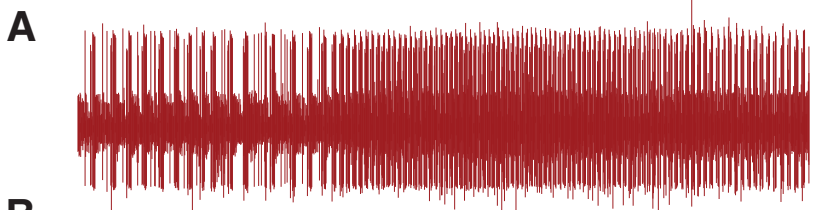

B
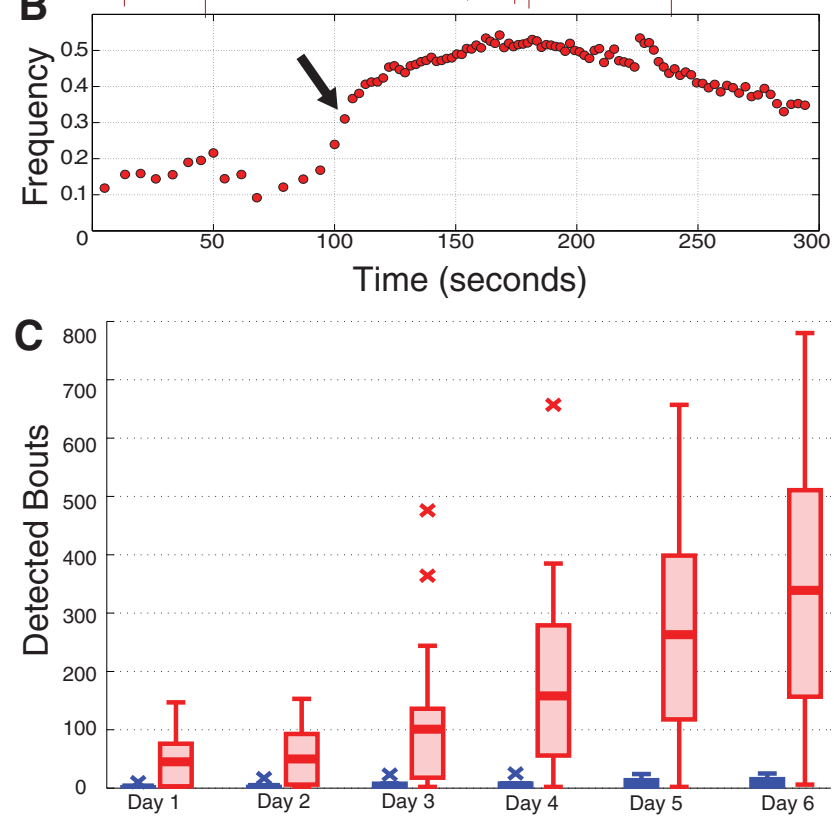

Figure 5 Analysis of bouting. $\boldsymbol{A}$, Example Ivn recording featuring one detected bout, visible here in the noticeable increase in pyloric cycle frequency starting mid-trace. $\boldsymbol{B}$, Frequency plot corresponding to the data in $\boldsymbol{A}$. Arrow designates the point at which the bout was detected. $\boldsymbol{C}$, Box plots show population data of the number of detected bouts by day for intact (blue) and decentralized (red) preparations.

previously reported, decentralized preparations displayed bouting behavior, and did so significantly more than intact preparations (Fig. $5 \mathrm{C}, p=0.006$, ANOVA). However, rather than presaging recovery to a stable, intact-like pyloric rhythm, we found that bouting increased over time, both for intact and decentralized preparations $(p<0.001$, ANOVA). Further, a significant interaction was observed between modulatory state and time $(p<0.001)$, as decentralized preparations tended to experience greater increases in bouting over time than did intact preparations. These observations are consistent with the hypothesis that bouting is indicative of a retuning process engaged by decentralization, which may then further increase over time.

\section{Previous definitions of recovery yield results similar to acute decentralization}

The earliest reports of recovery after decentralization (Thoby-Brisson and Simmers, 1998, 2000, 2002; Golowasch et al., 1999b) showed convincing examples of recovery, but little indication of how representative these examples were of the population. Subsequently, two definitions of recovery have also been used. Luther et al. (2003) defined recovery as a "strong and stable pyloric rhythm that lasted at least five hours". While the authors did not report population data regarding when these recoveries occurred or the frequencies typically observed, they did report that virtually all preparations met this definition at some point. Thus, to implement an examination of this definition, we selected the fastest $5 \mathrm{~h}$ stretch of decentralized data for each preparation, and quantified features of pyloric rhythms observed during these periods. When we compared the fastest $5 \mathrm{~h}$ stretches of pyloric data in the long-term recordings to acutely decentralized preparations of the STNS, we found that the observed rhythms were nearly indistinguishable from those observed at $30 \mathrm{~min}$ following decentralization. No significant differences were observed between these $5 \mathrm{~h}$ periods and acutely decentralized pyloric rhythms for pyloric cycle frequency, PD off-phase, LP on-phase, or LP off-phase. However, these $5 \mathrm{~h}$ stretches did show significantly more cycle-to-cycle variability than that of acutely decentralized preparations ( $p=0.023)$, consistent with our observation that bouting increases over time in longterm preparations (see Fig. 5). However, significant differences were observed between the $5 \mathrm{~h}$ stretches and rhythms produced by intact preparations for pyloric frequency (Fig. 6B, $p<0.001$ ), cycle-to-cycle variability (Fig. $6 \mathrm{C}, p<0.001$ ), PD off-phase (Fig. 6D, $p<0.001$ ), LP on-phase (Fig. 6E, $p=0.004$ ), and LP off-phase (Fig. 6F, $p<0.001$ ). Thus, the $5 \mathrm{~h}$ "fast stretches" resemble more closely those following decentralization than they do preparations that have not been decentralized.

A second definition of recovery applied in previous literature is the time to first bout (Zhang and Golowasch, 2007, 2011; Zhang et al., 2009). We found no correlation between the time to first bout and the time of onset of the fastest $5 \mathrm{~h}$ stretch (Fig. $6 \mathrm{~A}, p=0.537$ ), suggesting that these two definitions do not measure the same thing, although both are likely to be indicative that changes in excitability are ongoing in the decentralized preparations.

\section{Regular saline exchanges excite the pyloric rhythm}

In our first experiments, we placed the preparations in a temperature-controlled sterile incubator and, instead of continuous superfusion, we changed the saline once per day. These preliminary experiments showed that the act of exchanging saline itself can activate the pyloric rhythm. We demonstrated this directly in a population of 10 long-term decentralized preparations in which saline was exchanged at least once per day by removal of the dish from the incubator and replacement with fresh, temperature-matched saline. Figure 7A shows an example frequency versus time plot for an experiment in which the first daily saline exchange produced a long-lasting activation of the pyloric rhythm (Fig. 7B). We quantified the extent to which preparations were affected by this procedure by averaging pyloric frequencies for each preparation in the $1 \mathrm{~h}$ before and the $1 \mathrm{~h}$ following saline exchanges. Saline exchanges, on average, increased the frequency for all preparations examined (Fig. 7C, $p<0.001$ ). We compared the frequencies observed in this population to those of time-matched stretches of data from continuously su- 
A

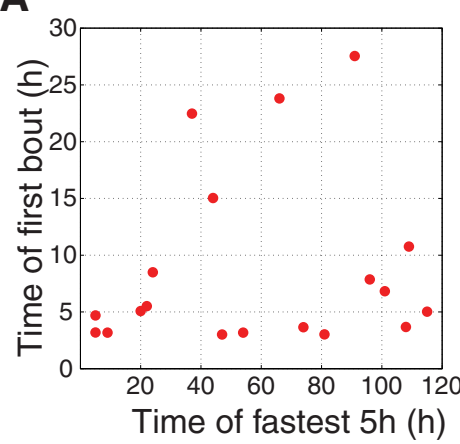

D

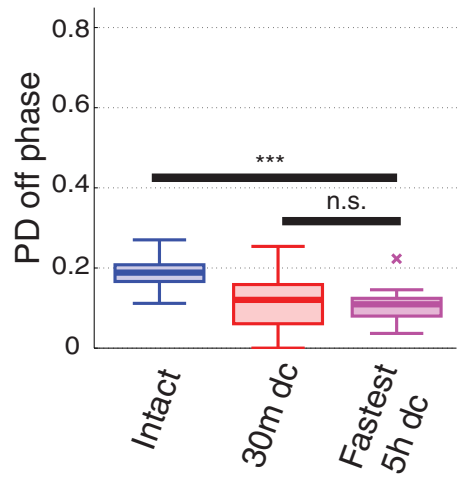

B

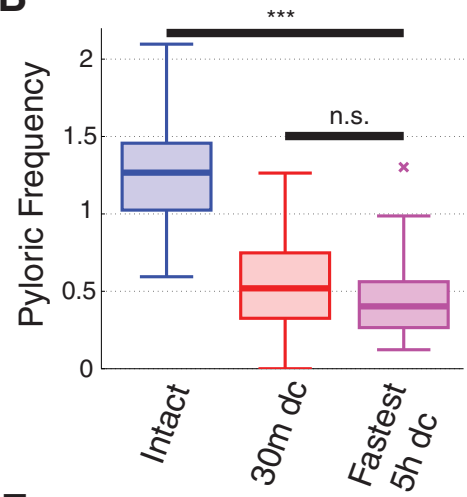

E

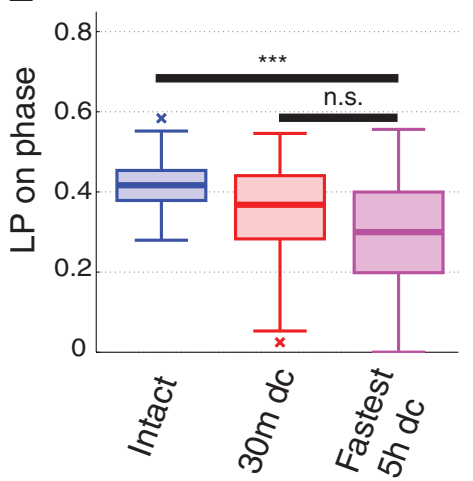

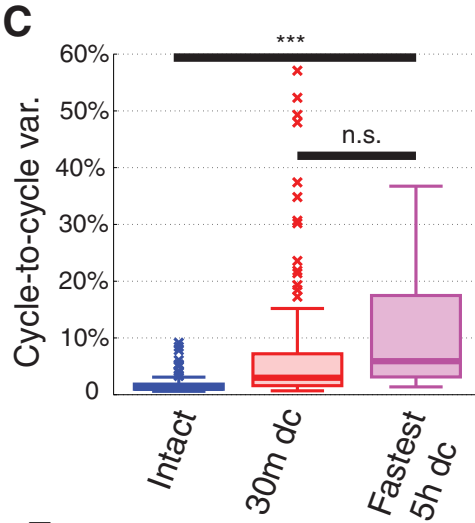

F

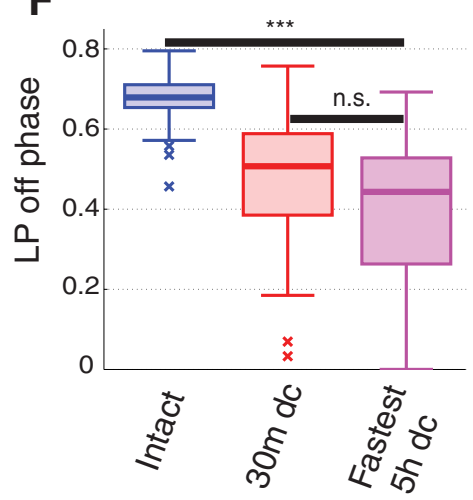

Figure 6 Analysis of previously used measures of recovery. $\boldsymbol{A}$. Two previously described definitions of recovery (time to first bout, and $5 \mathrm{~h}$ strong and steady rhythm) fail to correlate. $\boldsymbol{B}-\boldsymbol{F}$, Box plots show population data of intact (blue), 30 min decentralized (dc; red), and the fastest $5 \mathrm{~h}$ post-decentralization period of data from each decentralized preparation within the first $120 \mathrm{~h}$. n.s., not significant; $* * * p<0.001$.

perfused preparations and found that continuously superfused frequencies were significantly lower than frequencies shortly following saline exchanges $(p=$ $0.02)$, but not significantly different than frequencies prior to saline exchanges.

\section{Discussion}

In the early days of neuroscience, many fundamental discoveries and observations were reported with no indication of their reliability, although presumably the careful scientists of those days repeated experiments enough times to convince themselves of the reproducibility of their observations. For example, in the first paper that reports the results of the removal of the descending modulatory inputs to the STG of the lobster, Panulirus interruptus, Russell (1979) presented exquisite intracellular recordings showing the change in the waveforms of several pyloric rhythm neurons, but there are no n's or statistics reported in the paper. In these early days, data were often collected by filming the oscilloscope screen, so it was routine to only have a snapshot or a stretch of data for later analysis. Moreover, in the absence of digital computers, data analysis meant measuring with rulers, or counting spikes or bursts by hand, again making it difficult to analyze long-stretches of data, even had it been reasonable to collect it.
We have undergone a complete transformation in the way in which we collect, store, and analyze data, and it is to be expected that more complete analysis of much larger data sets will force some modifications of what we learned from the earlier workers, although a remarkably large number of early observations are validated by later studies.

Additional complications have arisen that may require reevaluations or reinterpretations of the conclusions of already published work. For example, work on the stomatogastric nervous system has been performed on more than 10 different species of decapod crustaceans, including lobsters, crabs, crayfish, and shrimp. While almost all of the big-picture general principles that have come from work on the stomatogastic nervous system are revealed in all of these species, each species has its own idiosyncratic properties, and it has been one of our challenges to exploit these differences while not forgetting that they exist. This is relevant to the present study because the work on recovery of function subsequent to decentralization has been done on several species.

A thornier issue arises because we routinely study adult wild-caught animals (by carapace width, approximately 5-7 inches) that have lived in the ocean for multiple years before they are caught and sold to commercial distributors. They are then held in running sea-water tanks for an 
A

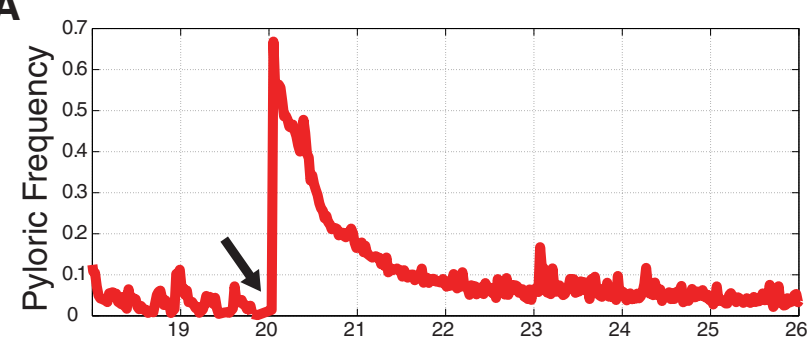

B Hours post-decentralization

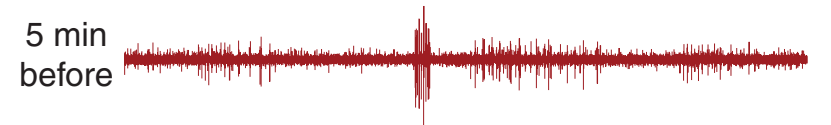
10 min
after 1 hour
after

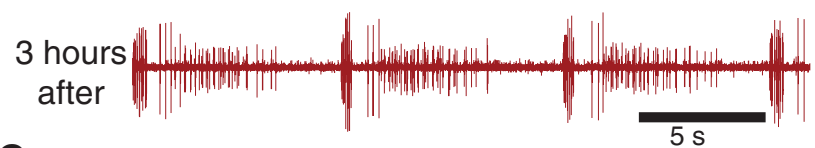

C

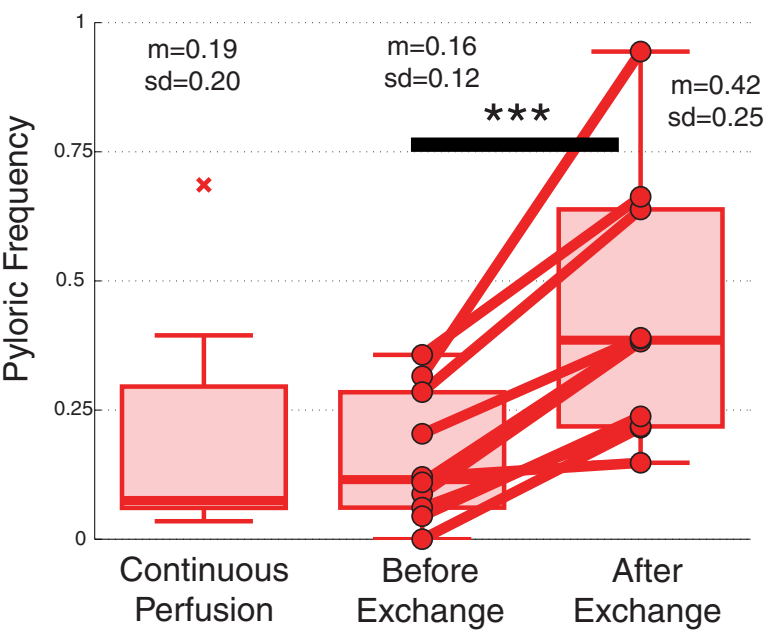

Figure 7 Daily saline exchanges transiently activate the pyloric rhythm. $\boldsymbol{A}$, Example pyloric cycle frequency plot for an $8 \mathrm{~h}$ stretch surrounding a saline exchange that transiently activates the pyloric rhythm (done at arrow). $\boldsymbol{B}$, Raw data from the same preparation reveals an increased frequency lasting several hours. C, Population data showing the average effect of exchanging saline in 10 long-term decentralized preparations. Leftmost box shows time-matched data from continuously superfused preparations. $* * * p<0.001$.

indeterminate period of time before they arrive in our laboratories. Consequently, we have no idea if we are sampling the same population of animals over time, or when the animals themselves are modified by a changing local environment. For example, after a particularly warm winter, the pyloric rhythms in preparations of $C$. borealis were far more robust in response to high temperatures than preparations from several prior years (Marder et al., 2015). Therefore, comparisons of data collected recently with those collected many years ago may be complicated by the non-stationarity of the animal population. That said, none of the previous studies on the effects of longterm decentralization had the statistical power and continuous recordings of the data presented here.

\section{Variability in response to acute decentralization}

The control data presented here (Fig. 1) before removal of the descending inputs are similar to those previously published (Goaillard et al., 2009), albeit collected 5-7 years apart by different investigators. The two data sets have similar means and also show a wide range of starting frequencies, with the range being slightly larger in the data shown here, which may not be surprising since the $n$ is almost twice as large.

Despite the large number of papers that have used decentralization to decrease the activity of STG preparations, this paper shows the first quantitative description of the effects of decentralization on the cycle frequency and phases of the pyloric rhythm. The population response to decentralization was robust, and every individual preparation slowed in response to decentralization. That said, only about $10 \%$ of the preparations actually stopped entirely after 30 min of removal of the descending modulatory inputs, and approximately the same number showed frequencies more characteristic of preparations with the descending inputs intact (Fig. 1D).

Another new observation made in this study is the difference in the phase of the LP neuron's activity under the two conditions. Phase maintenance of the pyloric neurons across frequency has been viewed as one of the hallmarks of the pyloric rhythm (Hooper, 1997; Manor et al., 2003; Bucher et al., 2005; Mouser et al., 2008; Goaillard et al., 2009; Tang et al., 2010), and our data resemble closely those of previous studies for the control, modulatory inputs intact condition (Fig. 1E). Nonetheless, in the decentralized case, the phase is not constant as frequency is varied, but instead is advanced at lower frequencies. This is easy to understand as the pacemaker burst cannot maintain constant duty cycle at arbitrarily slow frequencies. It is interesting that the transition from phase compensated to non-compensated comes around the low end of the frequencies seen in the intact preparations. This frequency-dependent distinction between phase-compensated and non-phase-compensated pyloric rhythms has not been previously shown.

\section{Within-preparation stability and across preparation variability in long-term recordings}

We maintained STGs for many days after dissection while slowly superfusing with physiological saline. When the descending modulatory inputs were left intact, each preparation maintained a characteristic average frequency that was within the distribution of frequencies seen in freshly dissected preparations. Likewise, decentralized preparations also maintained an approximately characteristic average frequency that again was within the distribution of frequencies seen in freshly dissected and acutely decentralized preparations. That said, there was 
considerably more jitter in the behavior of the decentralized preparations, and there were examples of extended periods of time when an individual preparation either sped up or slowed down. Had we not been recording continuously for many days, but sampling intermittently, some of these frequency changes might have looked as if the preparations were recovering from the effects of decentralization. Another possible confound is the effect of changing saline, which elicits several hours of higher frequency, normal-looking pyloric rhythms (Fig. 7). There are many potential factors that could contribute to this observation. Mechanical stimulation from the saline exchange operation may excite neurons directly, or cause neuromodulators to be released from the severed axon terminals of the stn. Temperature increases caused by prolonged opening of the incubator, or movement of the preparation out of the incubator could cause an increase in frequency. A depletion of dextrose or oxygen may slow the rhythm over time and leave it primed to increase rapidly following replenishment. A build-up of some unknown metabolic factor near the neurons of the STG, carried away regularly under conditions of continuous superfusion, could be responsible. It is unclear whether any of the previous reports describing recovery of function benefitted from this kind of stimulation by saline changes.

\section{Long-term changes in excitability}

It is without doubt that changing the modulatory environment and activity of neurons, either in isolation or in circuits, evokes changes in excitability (Turrigiano et al., 1994, 1995; Thoby-Brisson and Simmers, 1998, 2000, 2002; Desai et al., 1999; Golowasch et al., 1999a; Cudmore and Turrigiano, 2004; O'Leary et al., 2010; Temporal et al., 2014), and these kinds of excitability changes may be important for eventually understanding regulation of neuronal excitability after events such as spinal cord damage or other large lesions. For this reason, the idea of complete recovery of function after removal of descending modulatory inputs is extremely attractive. Nonetheless, whether or not full recovery occurs routinely, it is plausible that many changes in channel expression are triggered by a dramatic loss of descending modulatory input and consequent decreases in activity (Khorkova and Golowasch, 2007; Temporal et al., 2014). Because there are so many neuromodulators released into the neuropil of the STG (Billimoria et al., 2005; Marder and Bucher, 2007; Cape et al., 2008; Blitz and Nusbaum, 2011; Marder, 2012), and their effects are found on every neuron of the STG (Swensen and Marder, 2000, 2001; Marder and Bucher, 2007; Harris-Warrick and Johnson, 2010), even if loss of neuromodulatory control triggers a series of compensatory changes, these homeostatic changes (O'Leary et al., 2013, 2014) might be slow to occur, or might require a significant period of time of more complete inactivity to be fully elicited. The bouts that were seen here and in previous studies may be indications of an ongoing network retuning process (Luther et al., 2003; Zhang and Golowasch, 2007, 2011), which was triggered more rapidly by the decentralization but to a lesser extent by removal from the animal, with its sensory and hormonal inputs.

One of the features of the previous reports of pyloric rhythm recovery is that the frequencies of the recovered rhythms were always relatively slow, in the range of those we recorded in both the acute and long-term conditions. It would be interesting to see if more pronounced recoveries of pyloric rhythms occur in a large group of animals that fall silent when the neuromodulatory inputs are acutely removed.

As we enter the era of "big data", it is clear that those of us who work on wild-caught animals should adopt more strict standards of reporting, to the extent to which we are able, of the dates and sources of the animals we use for each study. In so doing, future generations of scientists may find it easier to find patterns in the variability we see among the individuals in these wild-caught animals.

\section{REFERENCES}

Bal T, Nagy F, Moulins M (1994) Muscarinic modulation of a patterngenerating network: control of neuronal properties. J Neurosci 14:3019-3035. Medline

Billimoria CP, Li L, Marder E (2005) Profiling of neuropeptides released at the stomatogastric ganglion of the crab, Cancer borealis with mass spectrometry. J Neurochem 95:191-199. CrossRef Medline

Blitz DM, Nusbaum MP (2011) Neural circuit flexibility in a small sensorimotor system. Curr Opin Neurobiol 21:544-552. CrossRef Medline

Blitz DM, Nusbaum MP (2012) Modulation of circuit feedback specifies motor circuit output. J Neurosci 32:9182-9193. CrossRef Medline

Bucher D, Prinz AA, Marder E (2005) Animal-to-animal variability in motor pattern production in adults and during growth. J Neurosci 25:1611-1619. CrossRef Medline

Cape SS, Rehm KJ, Ma M, Marder E, Li L (2008) Mass spectral comparison of the neuropeptide complement of the stomatogastric ganglion and brain in the adult and embryonic lobster, homarus americanus. J Neurochem 105:690-702. CrossRef Medline

Cudmore RH, Turrigiano GG (2004) Long-term potentiation of intrinsic excitability in LV visual cortical neurons. J Neurophysiol 92: 341-348. CrossRef Medline

Desai NS, Rutherford LC, Turrigiano GG (1999) Plasticity in the intrinsic excitability of cortical pyramidal neurons. Nat Neurosci 2:515-520. CrossRef Medline

Eisen JS, Marder E (1982) Mechanisms underlying pattern generation in lobster stomatogastric ganglion as determined by selective inactivation of identified neurons. III. Synaptic connections of electrically coupled pyloric neurons. J Neurophysiol 48:1392-1415. Medline

Goaillard JM, Taylor AL, Schulz DJ, Marder E (2009) Functional consequences of animal-to-animal variation in circuit parameters. Nat Neurosci 12:1424-1430. CrossRef Medline

Golowasch J, Abbott LF, Marder E (1999a) Activity-dependent regulation of potassium currents in an identified neuron of the stomatogastric ganglion of the crab cancer borealis. J Neurosci 19: RC33Medline

Golowasch J, Casey M, Abbott LF, Marder E (1999b) Network stability from activity-dependent regulation of neuronal conductances. Neural Comput 11:1079-1096. Medline

Harris-Warrick RM, Johnson BR (2010) Checks and balances in neuromodulation. Front Behav Neurosci 4:47. CrossRef Medline

Harris-Warrick RM, Marder E, Selverston Al, Moulins M (1992) Dynamic biological networks. the stomatogastric nervous system. Cambridge: MIT. 
Hooper SL (1997) Phase maintenance in the pyloric pattern of the lobster (Panulirus interruptus) stomatogastric ganglion. J Comput Neurosci 4:191-205.

Khorkova O, Golowasch J (2007) Neuromodulators, not activity, control coordinated expression of ionic currents. J Neurosci 27: 8709-8718. CrossRef Medline

Luther JA, Robie AA, Yarotsky J, Reina C, Marder E, Golowasch J (2003) Episodic bouts of activity accompany recovery of rhythmic output by a neuromodulator- and activity-deprived adult neural network. J Neurophysiol 90:2720-2730. CrossRef Medline

MacLean JN, Zhang Y, Johnson BR, Harris-Warrick RM (2003) Activity-independent homeostasis in rhythmically active neurons. Neuron 37:109-120. Medline

MacLean JN, Zhang Y, Goeritz ML, Casey R, Oliva R, Guckenheimer J, Harris-Warrick RM (2005) Activity-independent coregulation of $I_{A}$ and $i_{h}$ in rhythmically active neurons. J Neurophysiol 94:36013617. CrossRef Medline

Manor Y, Bose A, Booth V, Nadim F (2003) Contribution of synaptic depression to phase maintenance in a model rhythmic network. $J$ Neurophysiol 90:3513-3528. CrossRef Medline

Marder E (2012) Neuromodulation of neuronal circuits: back to the future. Neuron 76:1-11. CrossRef Medline

Marder E, Bucher D (2007) Understanding circuit dynamics using the stomatogastric nervous system of lobsters and crabs. Annu Rev Physiol 69:291-316. CrossRef Medline

Marder E, Haddad S, Goeritiz ML, Rosenbaum P, Kispersky T (2015) How can motor systems retain performance over a wide temperature range? Lessons from the crustacean stomatogastric nervous system. J Comp Physiol A Neuroethol Sens. In press. doi:10.1007/ s00359-014-0975-2.

Maynard DM (1972) Simpler networks. Ann N Y Acad Sci 193:59-72. Medline

Maynard DM, Dando MR (1974) The structure of the stomatogastric neuromuscular system in Callinectes sapidus, Homarus americanus and Panulirus argus (Decapoda crustacea). Philos Trans R Soc Lond (Biol) 268:161-220. Medline

Mizrahi A, Dickinson PS, Kloppenburg P, Fenelon V, Baro DJ, HarrisWarrick RM, Meyrand P, Simmers J (2001) Long-term maintenance of channel distribution in a central pattern generator neuron by neuromodulatory inputs revealed by decentralization in organ culture. J Neurosci 21:7331-7339.

Moulins M, Cournil I (1982) All-or-none control of the bursting properties of the pacemaker neurons of the lobster pyloric pattern generator. J Neurobiol 13:447-458. CrossRef Medline

Mouser C, Nadim F, Bose A (2008) Maintaining phase of the crustacean tri-phasic pyloric rhythm. J Math Biol 57:161-181. CrossRef Medline

Nusbaum MP, Beenhakker MP (2002) A small-systems approach to motor pattern generation. Nature 417:343-350. CrossRef Medline

Nusbaum MP, Blitz DM, Swensen AM, Wood D, Marder E (2001) The roles of co-transmission in neural network modulation. Trends Neurosci 24:146-154. Medline

O'Leary T, van Rossum MC, Wyllie DJ (2010) Homeostasis of intrinsic excitability in hippocampal neurones: dynamics and mechanism of the response to chronic depolarization. J Physiol 588:157170.

O'Leary T, Williams AH, Caplan JS, Marder E (2013) Correlations in ion channel expression emerge from homeostatic tuning rules. Proc Natl Acad Sci U S A 110:E2645-E2654.

O'Leary T, Williams AH, Franci A, Marder E (2014) Cell types, network homeostasis, and pathological compensation from a biologically plausible ion channel expression model. Neuron 82:809-821.
Russell DF (1976) Rhythmic excitatory inputs to the lobster stomatogastric ganglion. Brain Res 101:582-588. Medline

Russell DF (1979) CNS control of pattern generators in the lobster stomatogastric ganglion. Brain Res 177:598-602. Medline

Selverston Al, Moulins M (1985) Oscillatory neural networks. Annu Rev Physiol 47:29-48. CrossRef Medline

Selverston Al, Moulins M (1987) The crustacean stomatogastric system. Berlin: Springer-Verlag.

Selverston Al, Russell DF, Miller JP, King DG (1976) The stomatogastric nervous system: structure and function of a small neural network. Prog Neurobiol 7:215-290. Medline

Swensen AM, Marder E (2000) Multiple peptides converge to activate the same voltage-dependent current in a central patterngenerating circuit. J Neurosci 20:6752-6759. Medline

Swensen AM, Marder E (2001) Modulators with convergent cellular actions elicit distinct circuit outputs. J Neurosci 21:4050-4058. Medline

Tang LS, Goeritz ML, Caplan JS, Taylor AL, Fisek M, Marder E (2010) Precise temperature compensation of phase in a rhythmic motor pattern. PLoS Biol 8:e1000469. CrossRef Medline

Temporal S, Desai M, Khorkova O, Varghese G, Dai A, Schulz DJ, Golowasch J (2012) Neuromodulation independently determines correlated channel expression and conductance levels in motor neurons of the stomatogastric ganglion. J Neurophysiol 107:718727. CrossRef Medline

Temporal S, Lett KM, Schulz DJ (2014) Activity-dependent feedback regulates correlated ion channel mRNA levels in single identified motor neurons. Curr Biol 24:1899-1904. CrossRef Medline

Thoby-Brisson M, Simmers J (1998) Neuromodulatory inputs maintain expression of a lobster motor pattern-generating network in a modulation-dependent state: evidence from long-term decentralization in vitro. J Neurosci 18:212-2225.

Thoby-Brisson M, Simmers J (2000) Transition to endogenous bursting after long-term decentralization requires de novo transcription in a critical time window. J Neurophysiol 84:596-599. Medline

Thoby-Brisson M, Simmers J (2002) Long-term neuromodulatory regulation of a motor pattern-generating network: maintenance of synaptic efficacy and oscillatory properties. J Neurophysiol 88: 2942-2953. CrossRef Medline

Turrigiano G, Abbott LF, Marder E (1994) Activity-dependent changes in the intrinsic properties of cultured neurons. Science 264:974-977. Medline

Turrigiano G, LeMasson G, Marder E (1995) Selective regulation of current densities underlies spontaneous changes in the activity of cultured neurons. J Neurosci 15:3640-3652. Medline

Zhang Y, Golowasch J (2007) Modeling recovery of rhythmic activity: hypothesis for the role of a calcium pump. Neurocomputing 70: 1657-1662. CrossRef Medline

Zhang Y, Golowasch J (2011) Recovery of rhythmic activity in a central pattern generator: analysis of the role of neuromodulator and activity-dependent mechanisms. J Comput Neurosci 31:685699. CrossRef Medline

Zhang Y, Khorkova O, Rodriguez R, Golowasch J (2009) Activity and neuromodulatory input contribute to the recovery of rhythmic output after decentralization in a central pattern generator. J Neurophysiol 101:372-386. CrossRef Medline

Zhang Y, Oliva R, Gisselmann G, Hatt H, Guckenheimer J, HarrisWarrick RM (2003) Overexpression of a hyperpolarizationactivated cation current (ih) channel gene modifies the firing activity of identified motor neurons in a small neural network. $J$ Neurosci 23:9059-9067. 